\title{
Research on the Relationship Between Strategic Human Resource Management and Organizational Performance Based on Contingency Mode
}

\author{
Pingping Liu \\ Department of Human Resource Management, Beijing Wuzi University, Beijing, China
}

Email address:

pingpl@163.com

To cite this article:

Pingping Liu. Research on the Relationship Between Strategic Human Resource Management and Organizational Performance Based on Contingency Mode. Journal of Human Resource Management. Vol. 4, No. 5, 2016, pp. 55-60. doi: 10.11648/j.jhrm.20160405.12

Received: August 29, 2016; Accepted: September 14, 2016; Published: October 9, 2016

\begin{abstract}
At present, there are three modes studying on the relationship between strategic human resource management and organizational performance. These modes are universality mode, form mode and contingency mode. The paper firstly analyses on the characteristics of these three modes. And then, it infers the need for the use of contingency mode studying on the relationship between strategic human resource management and organizational performance. Secondly, it measures the standard of the organizational performance. At last, the paper takes the qualitative research method to study on the relationship between strategic human resource management and organizational performance, what factors influence on the relationship between the two, and the mediating variables and how to influence the process. It tries to provide a basis for subsequent research.
\end{abstract}

Keywords: Contingency Mode, Strategic Human Resource, Organizational Performance

\section{Relationship Between Strategic Human Resource Management and Organizational Performance}

The proposal of different theoretical framework of strategic human resource management reflects the deepening of strategic human resource management research, but it also shows that it does not form an unified theoretical model of strategic human resource management on the enterprise organizational performance impact mechanism. From the current theory, the relationship between strategic human resource management and organizational performance is also a "black box" relationship [1]. From a practical point of view, mediating variables and impact process of human resource management practices affecting organizational performance have not been very well supported by the data, and this is the current field of strategic human resource management researchers focus of the study.

In short, in theory, currently the most important challenge in this direction is to determine how many variables between strategic human resources management and organizational performance. That means to determine the number of mediating between the dependent variable and the independent variable, that is, how many boxes in this big black box to be placed in the end. Because of the complexity of such a mechanism, therefore, in theory, the possibility of the addition of more mediating is almost always present. At present, this work is not yet complete. Consistent achievement is only limited to have an intermediary between the two variables, but as a measure of how many and various variables on what level, it cannot be determined. So far no one model has been recognized as determined to explain the mechanism. It is still a black box between strategic human resource management and organizational performance, which also causes an increase in uncertainty in the mechanism of strategic human resource management and organizational performance [2].

\section{Three Different Modes of Strategic Human Resource Management and Organization Performance}

\subsection{Universal Mode}

Currently, according to scholars in different logically examining the relationship between strategic human resource 
management and organizational performance followed, there are three modes between strategic human resource management and organizational performance, namely, universal mode, form mode and contingency mode.

The first is universal mode. It is the most easiest mode. Because it implies the relations of independent variable and the dependent variable are universal in different tissues. Universal view is that some of the human resource practices are often superior to other human resource practices, the use of these best practices can lead to better organizational performance. These practices are called strategic human resource practices, sometimes also referred to as the best human resource management practices. Because its resource-based view is contrary to the view. Therefore, it has been questioned.

\section{Promotion}

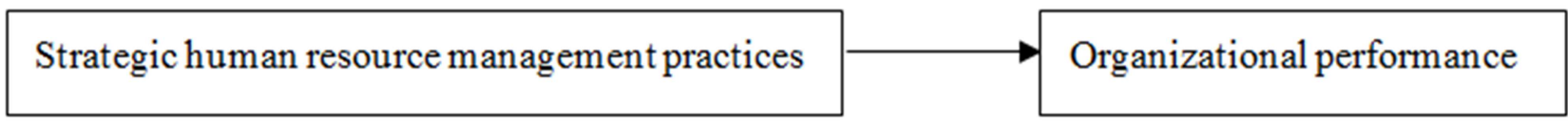

Figure 1. The logic diagram of universal mode.

\subsection{Form Mode}

The second mode is form mode. From the system point of view, form mode first of all emphasizes the formation of an effective human resource management system which forms through mutual complement and supports the human resource management activities in order to maximize internal matching. Then, these human resource management systems and the corresponding strategic form band together to maximize external consistency, in order to achieve internal and external matching strategic human resource management. Obviously, to some extent, opinions on form mode reflect the internal structure of the characteristics of human resource management system. Form mode suggests that human resource management activities have unlimited effective combination that can be achieved internally matched. As long as an organization of human resource management system used along this unified continuum, it is valid. However, in addition to achieving internal matching human resource management activities, the organization must match the maximum external human resource management activities. In reality, organizational strategy will deviate from the strategy type defined by scholars, and human resource system will deviate from the scholars defined the ideal type of human resource management system.

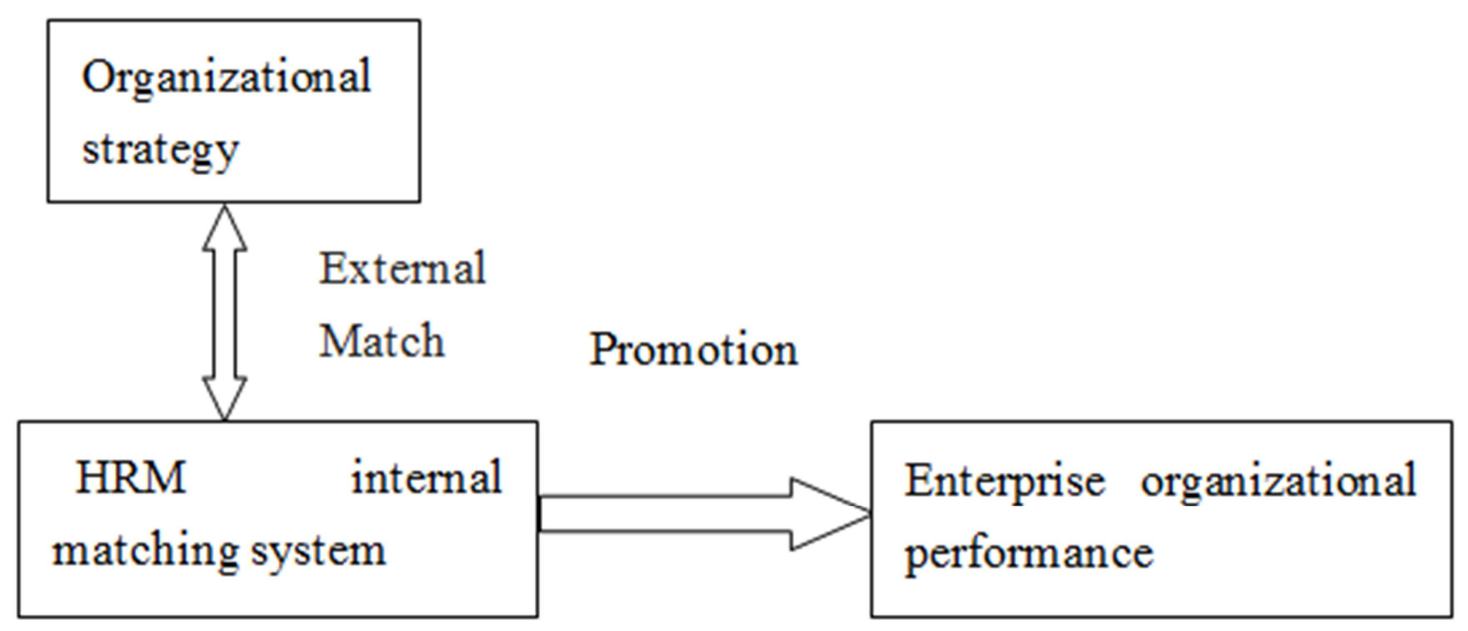

Figure 2. The logic diagram of form mode.

\subsection{Contingency Mode}

The third is contingency mode. From contingency mode point of view, the relationship between human resource management activities and organizational performance is affected on other contingency factors of organizational strategy [3]. Human resource management should be consistent with organizational needs, combined with business strategy, external factors or stages of development of the organization in order to effectively achieve organizational goals. Aspects on contingency mode try to show how HR practices consistent with the different strategic positioning, and how these practices are associated with the performance, which is obviously more complex than the universal mode. Because it implies interaction, rather than a simple linear relationship. In other words, the relationship between the independent variable and the dependent variable dealing with contingency mode is different from the different contingency variable. The methodology assumes that the relationship between the independent variable associated with the dependent variable will vary the level of the key contingency factors change. And organizational strategy is considered to be 
a major contingency factor.

\section{Promotion}

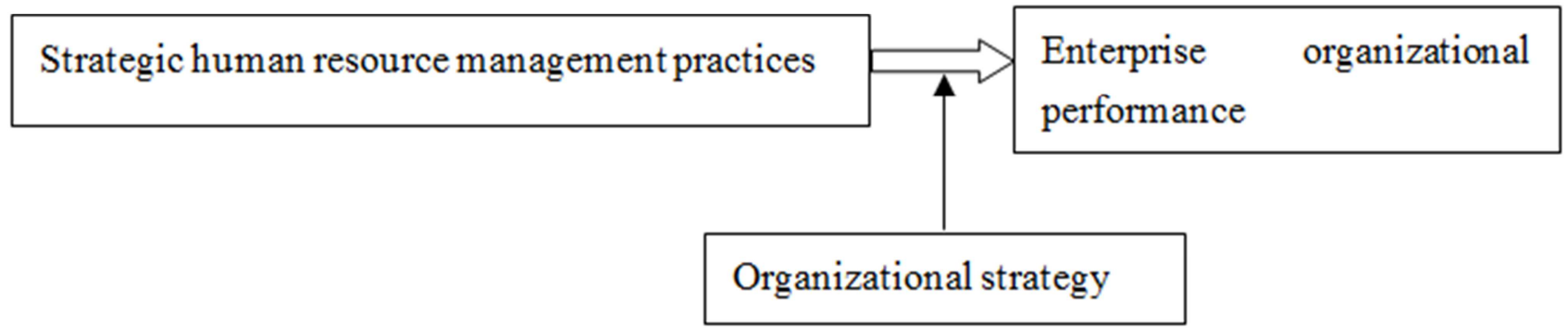

Figure 3. The logic diagram of contingency mode.

In relation between strategic human resource management and organizational performance, the relationship between the independent variables and related variables will vary with the level of the key contingency factors change. For contingency mode, the main problem is to determine the number of mediating between the dependent variable and the independent variable. The number of mediating variables and each variable on what kind of level measurement has not an accepted model to explain among these mechanisms. Therefore, this study will help to increase our understanding of the relationship between strategic human resource management and organizational performance, and promote the further development of relations between the two theories, and provide a reliable basis for the study of the relationship between the two in practice.

\section{Determination of Organizational Performance Metrics}

Strategic human resource management is a system. Activities of human resource management such as recruitment, training, etc. should be fully competitive advantage in favor of the formation of the organization, contributing to the formation of organizational strategy. Therefore, strategic human resource management is to organize a sustainable competitive advantage as the goal, to interact with the organization's business strategy management system [4]. In this system, human resource management is examined from two levels: the individual level of human resource management and organizational aspects of human resource management. On the individual level, human resource management guides to the competitive advantage organizations, namely the organizational resource through human resource management in order to gain an advantage. On the organizational level, human resource management guides to the organization's business strategy, namely organization through human resource management forming advantages of resource as the core business strategy, organization and development of sustainable competitive advantage in its interactive process [5].

Organizational performance refers to the operating efficiency of organization in a certain period of operation. Organizational and operational efficiency levels are mainly in terms of profitability, asset management levels, solvency and subsequent development capabilities. Early studies mainly used productivity to analyze organizational performance, and later, more and more scholars believe that organizational performance should be multidimensional and take a variety of evaluation methods to reflect a comprehensive picture of organizational performance. For example: Dong Shunqi believed that organizational performance mainly reflected in three aspects: efficiency, effectiveness and economy. Bray Depp also believed that organizational performance included three aspects: effectiveness, efficiency and variability. The combination of these three areas will ultimately determine a company's competitiveness. Compell summed 30 metrics to show the multi-faceted features of organizational performance. They comes down to five categories: productivity, overall performance, employee satisfaction, profit or ROI and employee turnover. From the literature, it can be found, most of indicators to measure organizational performance can be classified as two types of financial indicators and non-financial indicators. Financial performance refers to the performance indicators can be find in the financial statements. Non-financial performance is not apparent on the organization's financial records. Financial indicators is relatively easier to measure and get the data. Most non-financial indicators are customer satisfaction, employee turnover rate for the index and the financial index places profitability, return on investment and the relative market share of the most common.

Scholars commonly use Dyer \& Reeves views in the study of strategic human resource management and organizational performance relationship. They pointed out that in exploring human resource management system for corporate performance, in general organizational performance using different standards to measure, there are three commonly standards used: (1) HR outputs; (2) organizational outputs; (3) finance or accounting outputs. Comparison from Dyer \& Reeves [6] organizational performance metrics, it can be found indicators of human resource outputs and organizational outputs are mostly non-financial indicators. Therefore, organizational performance indicators are classified by this method, it can be represented in Figure 4. 


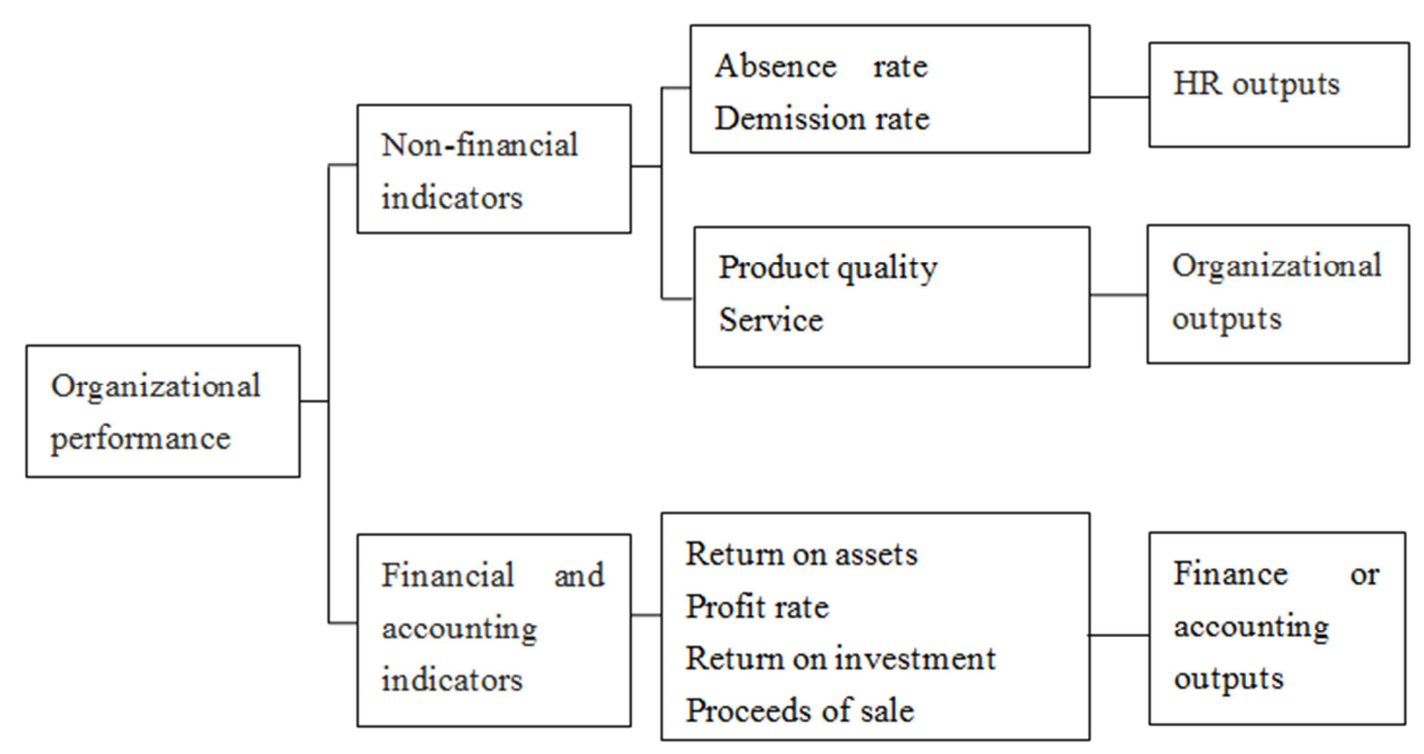

Figure 4. Organizational performance indicator structure.

\section{Mediating Variables}

From the existing research, the study of mediating variables between strategic human resource management and organizational performance bases on three main theoretical models: resource-based theory, human capital theory and the role of behavior theory [7]. High quality human capital has the potential to improve organizational performance, but the potential to be converted to the final outcome, employee attitudes and behaviors are the catalyst for transformation. And if you ignore organizational core resources and capabilities to create and nurture, there may obscure our understanding of strategic human resource management affecting organizational performance mechanism of action. Therefore, based on the theory of integrative perspective, the impact of a common mechanism of these factors and those factors synergistic effect, which is the understanding of strategic human resource management has a strong theoretical contribution to the process of organizational performance, and also provides an empirical study a good framework.

Based on resource-based theory, human resource is seen as a strategic enterprise resource, through effective human resource management has been nurtured, resulting in high-performance business. Most unique of strategic human resource management system based on the theory of resource is human resource as a system, it is a strategic asset, with difficult transactions, difficult to imitate, scarce, unique features. This gives companies a competitive advantage. Competitive advantage of organizations through a rigorous selection process, ongoing training, high attractive compensation plans, supportive organizational culture as well as other strategic human resource management practices acquired. HR within the organization is seen as a mechanism to control scarce resource, it is necessary to control the ability to achieve the organization's strategic objectives. Scarcity of resource ensures that the inimitability competitors. Competitors to imitate a single HR practices is easier, but you want to copy the entire human resource management system by different combinations of human resource management practices formed are very difficult. Even if competitors can copy the entire human resource management system, but because of the replication of human resource management practices are not consistent with a particular strategy or internal situations of environmental organizations, copy cannot achieve the desired effect. Therefore, based on the resource-based theory studying on the relationship between strategic human resource management and organizational performance, it can be understood the organizational processes to create value through the strategic management of human resource and mechanisms in depth. Therefore:

Hypothesis 1: Strategic human resource management practices: human resource planning, specification recruitment, ongoing training, performance-oriented pay system, performance evaluation of goal-oriented are positively related to organizational performance.

Compared to other capital physical capital, human capital has the significant features. These features just make human capital to be the scarce, valuable, irreplaceable or imitation and difficult mobility. First, because human capital means not only competence, knowledge and skills, but also means that the time, health and longevity. It is a scarce resource. Secondly, human capital is incremental (human capital through continuous learning, in use, to increase own stock) and investment income multiplicity (human capital can not only generate monetary benefits, but also psychological and social benefits, etc.), which determines the value of the multidimensional nature of human capital. Thirdly, the variability, the multi-level, investing irreversible and difficult to measure of human capital also determines it is difficult to imitate and alternative [8]. And finally, the dependent between 
human capital and physical capital determines it is not easy mobility. In short, the characteristics of the human capital decide human capital can become a strategic asset, and it is the source of sustainable competitive advantage.

Human capital theory provides a framework for understanding the relationship between strategic human resource management and organizational performance. It emphasizes by investing in human capital to improve employee productivity. Based on the human capital theory, the researchers take human capital as a mediator between strategic human resource management and organizational performance. Human resource management practices can improve the knowledge, skills and abilities inherent in their employees, thereby enhance the organization's human capital content. When employees having human capital can create value for the customer, it becomes a source of competitive advantage [9]. In the empirical study, we tend to superimpose a global variable from the influence of each human capital investment activity to measure its impact on business performance. Therefore:

Hypothesis 2: Human capital is the mediator variable between strategic human resource management and the enterprise organizational performance.

In strategic human resource management systems, due to the attitude and behavior of staff required for each strategy different, HR practices of the organization will change. In other words, human resource management is an important tool for organizations to transfer the role of information and support to achieve the desired behavior, and the role of performance audit, in order to achieve organizational objectives. The organization's human resource management system implies employee role information desired by the organization. Employees take the appropriate behavior following this role information and resulting in different individual performance and organizational performance. The behavior of employees reflects their understanding and explaining of the human resource management system. Organizational behavior theory assumes that strategic human resource management practices as a tool for employee behavior, and that different strategies emphasize different rules of conduct. Effective human resource management system includes: accurately identify and implement the company's strategy behavior, provide an opportunity for staff to achieve the desired behavior, ensure that employees have the necessary competence, motivate employees to conduct efforts organizations need [10].

Applying the role behavior theory, scholars divide human resource management activities into human resources policy, HR procedure, human resource practices and HR processes and they consider these activities particularly human resource practices encourage members to show the different strategies needed role behavior, and the role behavior matching strategy is effective behavior. In other words, the appropriate inspired role behavior matching the strategic human resource management activities is the key to get a competitive advantage and improve organizational performance. Therefore:
Hypothesis 3: employee behavior and attitudes are the mediator variables of strategic human resource management and organizational performance.

In terms of organizational performance, organizational capacity is one of the key variables that influence performance. According to the theory of dynamic organizational capability, organizational skills including organizational strategy capacity, organizational integration capacity, and the individual within the organizational capacity. Organizational strategic capability is the ability to establish goals and appropriate decision-making ability, that ability on the strategic level of organizational vision, organizational and external environment matching. This ability depends on collaboration with senior management decision-making ability. Organizational integration capability integrate individual member ability distributed in the organization and integrate these abilities with other resources in the organization to create the desired system competency. The key of the formation of such capacity is senior management collaboration and integration capabilities in the organization. Ability within the organization based on the individual level refers to the key knowledge, skills and abilities in the distribution of the members within the organization. These capabilities mainly are from the "inner core" and "outer core" of the organization. Inner core is responsible for the innovation managers, technical experts and the staff at strategic positions. Outer core are those with trade skills employees. Therefore, to form a strategic organizational ability, the ability to integrate and individual capacity, it must obtain senior managers with decision-making and collaboration capability and it must obtain the inner core and outer core of the organization. The key to obtaining these respective managers and staff of the organization is human resource management practices. On the organization and the appropriate institutional arrangements concerned, it includes the power mechanisms within the organization, the establishment of job recruitment mechanism, compensation and incentives mechanism, talent development mechanism, promotion and exit mechanism. These institutions and arrangements are "blood" in the organization, to promote the formation and development of organizational capacity. And it is the result of the organization of human resource management practices. Therefore, in the formation and development of organizational capacity, in the tissue within a procedure corresponding system and arrangements, the organization of human resource management practices play a key role. Organizational capacity and appropriate internal organizational and institutional arrangements are important variables that affect organizational performance. Therefore:

Hypothesis 4: organizational capacity is the mediator variable of the strategic human resource management and organizational performance.

\section{Conclusion}

The main content of this paper is the use of qualitative research method to study the relationship between strategic 
human resource management and organizational performance. In the Chinese context, the study on strategic human resource management and organizational performance starts late, the research literature in this area is basically emerged after 2003. China have many industries, only research a few sectors such as manufacturing and other industry chain is not enough. So, on the basis of qualitative research, researchers can select the tertiary sector industries business in the Chinese economy gradually occupying the more important position to study and discuss on the relationship between strategic human resource management and organizational performance in the Chinese context. And we will contribute to research in this area.

\section{References}

[1] Kou yue, Jia zhiyong, Bai yun. A Review on the Theoretical Study of Strategic Human Resource Management from an Integrative Perspective. Management Review, 2014, 26 (12): 110-119.

[2] Huang bo, Jiang xinhui, Gu jianghong. The Relationship between HRM Policy \& Implementation and Organization Performance. Foreign Economics \& Management, 2016, 38 (5), 58-68.

[3] Wang lanyun, Su lei. Study of the relationship between the fit of strategic human resource management and organizational performance. Science and Technology Management Research, 2015 (9): 173-179.
[4] Song dian, Yuan yongzhi, Zhang weiwei. Cross-level research on strategic human resource management, innovative atmosphere and innovative behavior of employees. Science and Technology Management. 2011, 1: 29-33.

[5] Pan yongming, Mi guanxu. Strategic Human Resource Management: a competitive advantage for the organization. Jiangxi Social Sciences. 2009, 5: 41-43.

[6] DYER L., REEVES T. Human resource strategies and firm performance: what do we know and where do we need to go. International Journal of Human Resource Management, 2006, 45 (3): 337-355.

[7] Wang yajie, Dai jingxin. Strategic Human Resource Management, Firm Characteristics and Firm Performance. Science and Technology Management Research, 2014, 34 (4): 163-168.

[8] Wang zhaohui. A Literature Review of the Relationship between Strategic Human Resource Management and Organizational Ambidexterity. Foreign Economics \& Management, 2016 (3): 44-60.

[9] Gary Dessler, translation by Liu xin. Human resource management. Beijing: China Renmin University Press. 2010: 39-98.

[10] Mary, E G LINDSAY, M T The important of the employee perspective in the competency development of human resource professionals. Human Resource Management. 2006, 45 (3): 337-355. 